\title{
A cost-benefit analysis of improving trawl selectivity in the case of discards: The Nephrops norvegicus fishery in the Bay of Biscay
}

\author{
Claire Macher ${ }^{\mathrm{a}, \mathrm{b},{ }^{*}}$, Olivier Guyader ${ }^{\mathrm{a}}$, Catherine Talidec $^{\mathrm{c}}$ and Michel Bertignac ${ }^{\mathrm{d}}$
}

\footnotetext{
a IFREMER, Centre de Brest, Département d'Economie Maritime, BP 7029280 Plouzané, France

b UBO, Centre de Droit et d'Economie de la Mer, 12 rue de Kergoat Bat. C.S. 93837, 29238 Brest Cedex 3, France

c IFREMER, Station de Lorient, Département Sciences et Technologies Halieutiques, Laboratoire Ressources Halieutiques, 8 rue François Toullec, 56100 Lorient, France

d IFREMER, Centre de Brest, Département Sciences et Technologies Halieutiques, Laboratoire de Biologie des Pêcheries, BP 7029280 Plouzané, France
}

*: Corresponding author : Macher C., email address : $\underline{\text { Claire.Macher@ifremer.fr }}$

\begin{abstract}
:
The Nephrops trawl fishery is one of the most important fisheries in the Bay of Biscay. The fishery management essentially relies on conservation measures, a total allowed catch (TAC) for Nephrops together with a minimum landing size (MLS) and minimum trawl mesh size (70 mm stretched mesh). These measures have failed to prevent high discard levels of many species that characterize the fishery. Nephrops trawlers thus discard about half of their Nephrops catches in numbers (a third in weight) of which only $30 \%$ survive. Nephrops discards mainly occur in younger Nephrops age groups below the MLS. This is a waste for the already overexploited Nephrops stock as well as for the fleet. Based on a bio-economic simulation model, the paper analyses the consequences of several scenarios of improving Nephrops selectivity. The potential impacts of these scenarios on Nephrops biomass, landings, discards and economic indicators (e.g. rent) are examined and a cost-benefit analysis of each scenario is carried out. We show that a better exploitation pattern would benefit fisheries that have high level of discards. Reducing non-commercial Nephrops discards leads to positive net present values of rent with better value realized from the production potential and limited short-term losses for the fishing units. By taking account of the economic dynamics of increasing effort however, we show that selectivity measures are insufficient. Regulating access to the fishery is also required to ensure the sustainability of the fishery and a better exploitation of the production potential.
\end{abstract}

Keywords: Nephrops norvegicus; Bio-economic simulations; Cost-benefit analysis; Selectivity; Discards; Fisheries management

\section{Introduction}

Bottom trawls are known to be poor selective gears. Their use in a multi-species and multisize ecosystem induces catches of non targeted fishes or unwanted length grades of the targeted species. Much of this catch is often discarded with high mortality rates (Alverson et al., 1994). The French bottom trawler fleet targeting Nephrops in the bay of Biscay (ICES Divisions VIIla,b) is characteristic in this context. 
Based on a Total Allowed Catch (TAC) together with Minimum Landing Sizes (MLS) and a rather small minimum mesh size $(70 \mathrm{~mm}$ stretched mesh), present management rules have failed to prevent high levels of by-catches and discards of many species. Especially Norway Lobster (Nephrops norvegicus), Hake (Merluccius merluccius), Anglerfish (Lophius piscatorius and Lophius budegassa) and Megrim (Lepidorhombus whiffiagonis) are discarded. The poor gear selectivity and a MLS on Nephrops $(8.5 \mathrm{~cm}$ and $9 \mathrm{~cm}$ since 2005) are the main reasons for high discard levels of younger age groups of Nephrops observed in this fishery. In 2004, Nephrops discards represented $60 \%$ of the Nephrops caught in number of individuals (30\% in weight) (ICES, 2006) of which $70 \%$ die (Guéguen and Charuau, 1975). This leads to wasteful high fishing mortality on young Nephrops and therefore contributes to misexploitation (by growth over-fishing) of the Nephrops stock production potential. ICES thus reports the Nephrops stock is over-exploited compared to the maximum sustainable fishing mortality. To date, no quantitative assessment of potential benefits, from an improved exploitation pattern for the stock and the fleets, is available. This is however a key issue for fisheries management.

The benefits of size-selectivity measures, aimed at improving the exploitation pattern, appear evident in fisheries characterized by high level of by-catches and discards (Beverton and Holt, 1957; Ward 1994; Suuronen, 2006; Pascoe and Revill, 2004). Selectivity measures, such as increasing mesh-size or adopting more selective gear or devices (like Nephrops grids), avoid catches and discards of the youngest individuals. This increases the age at first capture, the catch per unit effort and the sustainable total yield (MacLennan; 1995; Stergiou et al., 1997; van Marlen, 2000; Kvamme and Fröysa., 2004; Salini et al., 2000). Improving selectivity leads to a more efficient exploitation of the stock's growth potential. More Nephrops thereby reach mature size and spawn. Furthermore, this smoothes fluctuation in recruitment and thus guarantees more even yields for the fishery. From an economic perspective, the catches contain larger individuals, which generally receive better prices per weight. Some studies, assessing impacts of selectivity measures, highlight likely high short-term losses for the fleet (Griffin et al., 1993; Ferro and Graham, 2000; Heikinheimo et al., 2006; Tschernij et al., 2004). In view of the uncertain long-term gains, the problem of high short-term losses is often used as an argument against the use of more selective gears. However, reducing discards does not necessarily mean a reduction in landings. When selectivity only affects the discarded fraction of the catches, landings can be unchanged at first and then increased.

The objective of this paper is to provide a cost-benefit analysis of improving selectivity measures in the case of the Nephrops fishery. We analyze transition phases and compare potential short-term losses to long-term gains. Few papers are available in the literature on this subject (see OECD 1997, 2000; Halliday and Pinhorn, 2002; Freese et al., 1995; Lucena and O'Brien, 2005; Boncoeur et al., 2000). A bio-economic deterministic simulation model of the Nephrops fishery in the Bay of Biscay is developed for this purpose. The model is based on an age-structured model for the Nephrops stock, with several fleets targeting Nephrops. The model produces different indicators over the simulation period, both at equilibrium and during the transition phases. Nephrops biomass, catch, landings, discards, gross revenue and producer surplus (rent), used for the cost-benefit analysis, are thus studied for six theoretical selectivity scenarios. The model assumes that effort is either constant or adjusted to profitability of the vessels. In this case, the endogenous effort model is based on similar approaches developed in other contexts (Lleonart et al., 2003; Guillen et al. 2004). This assumption implies that selectivity measures do not prevent "the race for fish". 
After a description of the Nephrops fishery, we present the framework of the bio-economic model. Results of cost-benefit analyses of selectivity scenarios are then discussed, assuming static or endogenous effort. The concluding section discusses limitations of selectivity measures for fisheries management.

\section{Material and methods}

Bio-economic modelling requires a good analysis of the conditions of exploitation in this fishery in order to assess the impacts of management measures, especially selectivity scenarios. This includes a description of the management rules, a characterization of the fleets involved in the fishery and of their exploitation pattern as well as an analysis of the status of the stock.

\subsection{The Nephrops fishery in the Bay of Biscay}

\section{Management rules}

Nephrops are targeted by bottom trawlers on a sand-muddy area called the "Grande Vasière" (ICES Divisions VIIIa,b). Nearly all the Nephrops landings from VIIIab are taken by French trawlers. The Nephrops trawler fleet is one of the most important segments of the French fleet in the Bay of Biscay. The fleet indeed represents about one quarter of the French trawlers in this area (Berthou et al, 2004). In 2003, 234 bottom trawlers were involved in the Nephrops fishery (Figure 1).

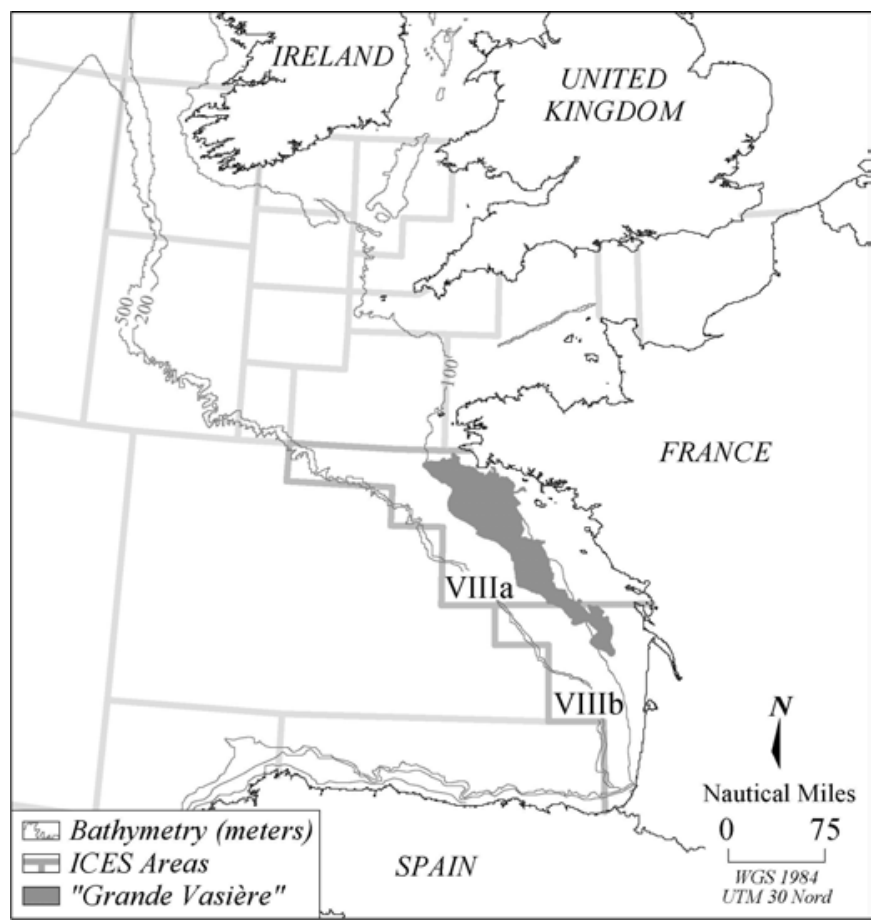

Figure 1: Nephrops Fishery in the Bay of Biscay (ICES Divisions VIIIa,b), Source: IFREMER 
The management of the Nephrops Fishery in the Bay of Biscay essentially relies on conservation measures. For a long-time, a Minimum Landing Size (MLS) of $26 \mathrm{~mm}$ Cephalothoracic Length, i.e. $8.5 \mathrm{~cm}$ total length, was fixed by French Producers' Organisations. Because of the market, this MLS was chosen larger than the European MLS (20 mm CL i.e. $7 \mathrm{~cm}$ total length). Since December 2005, a new French MLS regulation (9 $\mathrm{cm}$ total length) has been adopted.

Several regulations regarding mesh size were adopted successively these last few years. In 2000, minimum codend mesh size in the Bay of Biscay became $70 \mathrm{~mm}$ instead of the former $55 \mathrm{~mm}$ for Nephrops (Council Regulation (EC) No 850/98, diameter cod-end mesh size). A Total Allowable Catch (TAC) has been enforced since 1987 together with technical measures. In 2004, the TAC was set at 3150 tonnes with a French quota of $2961 \mathrm{t}$ (94\% of the TAC the remainder being allocated to Spain). The French quota is shared between Producers' Organisations but there is no vessel quota allocation. The Nephrops fleet has also been submitted to the national vessel decommissioning schemes (Guyader et al., 2007). This explains partially the decrease in number of vessels targeting Nephrops. Around 400 vessels were active in the fishery in 1978, 300 in 1987 and 230 have been still targeting Nephrops since 2000. However this decrease in fishing effort has been compensated at least in part by gains in vessel efficiency due to technical creeping (Marchal et al., 2007). In 2004, licences were also enforced and a numerus clausus of 250 Nephrops trawlers was adopted, whereas the fishery was in open access before. However no limitation on fishing effort (number of trips for example), gear or individual catches has been implemented.

\section{Fleet structure and landings composition}

The fleet is composed of trawlers with an average length of 15 meters, $235 \mathrm{~kW}$ of engine power and an average age of 19 years. During the 1990's, single trawls were progressively replaced by twin-trawls which are now the common gear used to target Nephrops. The mean crew size is three members. Nephrops trawlers spend around 200 days at-sea per year and the duration of the trips varies from 12 hours to 3 days. Table 1 provides key physical and economic characteristics of the Nephrops fleet and sub-fleets based on crew size segmentation. This segmentation is the result of a statistical analysis. Variability of gross revenues and cost structure per crew size category is indeed reduced compared to vessel length size segmentation.

\begin{tabular}{ccccccc}
\hline $\begin{array}{c}\text { Crew size } \\
\text { Categories }\end{array}$ & $\begin{array}{c}\text { Number of } \\
\text { vessels }\end{array}$ & Mean length $(\mathrm{m})$ & $\begin{array}{c}\text { Mean number of } \\
\text { days at sea } \\
\text { per year }\end{array}$ & $\begin{array}{c}\text { Mean Vessel } \\
\text { Value } \\
\text { (k Euros) }\end{array}$ & $\begin{array}{c}\text { Total Gross } \\
\text { return } \\
\text { (millions Euros) }\end{array}$ & $\begin{array}{c}\text { Average Gross } \\
\text { return } \\
\text { per vessel } \\
\text { (k Euros) }\end{array}$ \\
\hline$[1,2]$ & 53 & 12 & 199 & 191 & 8 & 153 \\
] $2 ; 3]$ & 70 & 15 & 199 & 304 & 19 & 279 \\
] $3 ; 4]$ & 54 & 16 & 201 & 368 & 18 & 343 \\
] $4 ; 5]$ & 50 & 17 & 217 & 532 & 24 & 482 \\
] $5 ;[$ & 10 & 18 & 225 & 801 & 6 & 630 \\
\hline
\end{tabular}

Table 1: Distribution of the vessels per crew category and mean characteristics for 2001-2003.

As crew size often varies along the year, the mean crew size per year might not be an integer. That explains the use of crew size category. The average gross revenue is 153 keuros for the [1-2] crew size vessels category and 630 keuros for the 5 and more crew size category.

The total gross revenue of the fleet was estimated to 82.4 million euros in 2003 for an added value of 45 million euros. In 2003, 3900 tonnes of Nephrops were landed, generating gross revenue of 33.2 million euros. Nephrops contribute on average $40 \%$ of the total gross revenue 
of the fleet. This proportion declines however from the Northern to the Southern part of the fleet (51 and $25 \%$ respectively). The other part of the total gross revenue comes from the multi-species landings that characterize this mixed fishery (Table 2).

\begin{tabular}{lccc}
\hline & $\begin{array}{c}\text { Production } \\
\text { (tonnes) }\end{array}$ & Value (kEuros) & $\begin{array}{c}\% \text { of the Total } \\
\text { Gross Revenue }\end{array}$ \\
\hline Northern fleet & & 3896 & $8 \%$ \\
\hline Anglerfish & 814 & 24993 & $52 \%$ \\
Nephrops & 3053 & 3408 & $7 \%$ \\
Hake & 934 & 3658 & $8 \%$ \\
Sole & 332 & 11852 & $25 \%$ \\
Other species & 5414 & 47808 & $100 \%$ \\
\hline Total Northern fleet & 10547 & & $5 \%$ \\
\hline Fleet from other regions & & 1485 & $25 \%$ \\
\hline Anglerfish & 268 & 7129 & $7 \%$ \\
Nephrops & 873 & 1848 & $16 \%$ \\
Hake & 508 & 4471 & $47 \%$ \\
Sole & 453 & 13300 & $100 \%$ \\
Other species & 5526 & 28234 & \\
\hline Total Other Regions & 7628 & & \\
\hline
\end{tabular}

Table 2: Mean Quantity, value and percentage of the total gross revenue of the main by-catches of the Northern and southern Nephrops fleets (2001-2003).

In order to consider the diversity in activity, species composition and size of the fishing units, ten Nephrops sub-fleets were consequently identified into the bio-economic model. This gives us the possibility to analyse the impact of management measures on different segments of the fleet, based on crew size categories and geographic segmentation.

\section{Nephrops landings and discards}

During the 1980's and early 1990's, Nephrops landings have been fluctuating between $4500 \mathrm{t}$ and $6100 \mathrm{t}$. After a period of decline to around 3200 tonnes in the late 1990's, landings showed a slightly increasing trend in recent years. Discarding proportion in number per age group based on data obtained from the observations and sampling on board (IFREMERObsmer) are presented in Figure 2. Most of the catches of Nephrops of the first two age groups are discarded of which $70 \%$ die (Guéguen and Charuau, 1975). Seventy percent of the population in number belong to the first two age groups. $11 \%$ of those two age groups are caught and $91 \%$ of those catches are discarded (ICES, 2004). In 2004, Nephrops discards were estimated at 1875 tonnes. Discards represent $60 \%$ of Nephrops caught in number and $30 \%$ in weight (ICES, 2006). In the Nephrops fishery, the main reason for discarding Nephrops is the Minimal Landing Size (MLS). Younger Nephrops age groups caught below the MLS are discarded.

The high level of catches and discards of younger age groups below the MLS contributes to economic inefficiency of the exploitation. Discards are made up of Nephrops that, if not caught, could be landed and sold later at a larger size and therefore a better price. Indeed, prices are raised with length (or age) of the Nephrops (Figure 2). 


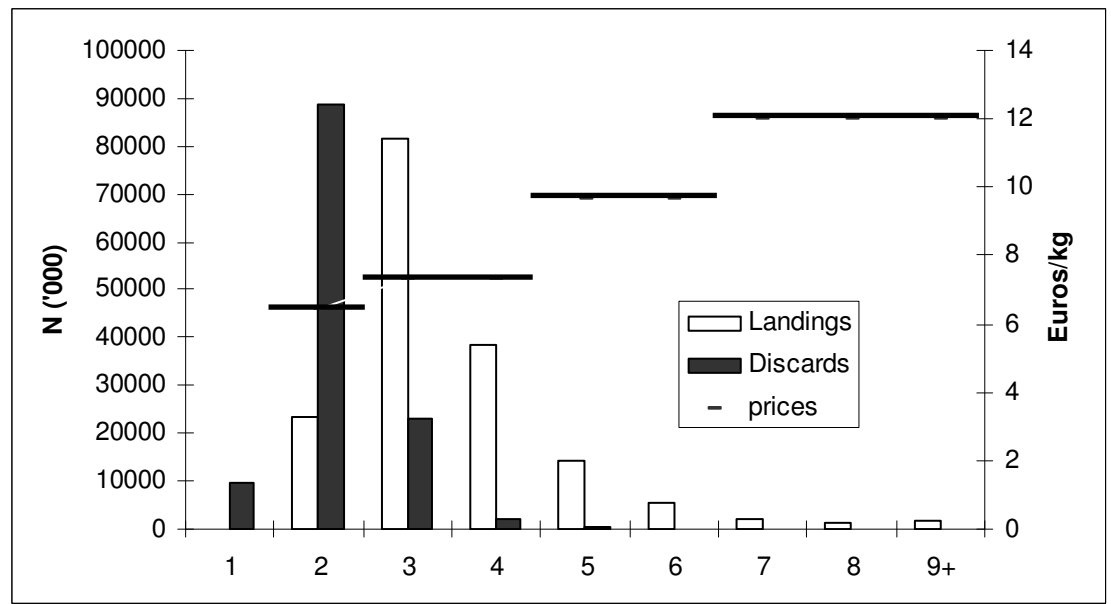

Figure 2: Landings and discards of Nephrops in number of individuals per age group (mean 2001-2003) and mean price per age group (2001-2003)

The ACFM (ICES, 2004) also underlined that current fishing mortality on young age groups, especially because of discards, is too high to yield the maximum level of production. This highlights the stakes of improving Nephrops size-selectivity and the potential benefits for the stock and the fleet of such management measure.

\section{The Nephrops Stock status}

Assessment for the Nephrops stock in ICES Divisions VIIIa,b has been conducted by ICES since 1987. Spawning Stock Biomass and recruitment seem to have increased since the late 1990's. The Nephrops Stock age structure and the exploitation pattern resulting from effort applied to the stock by Nephrops trawlers are given in Figure 3.

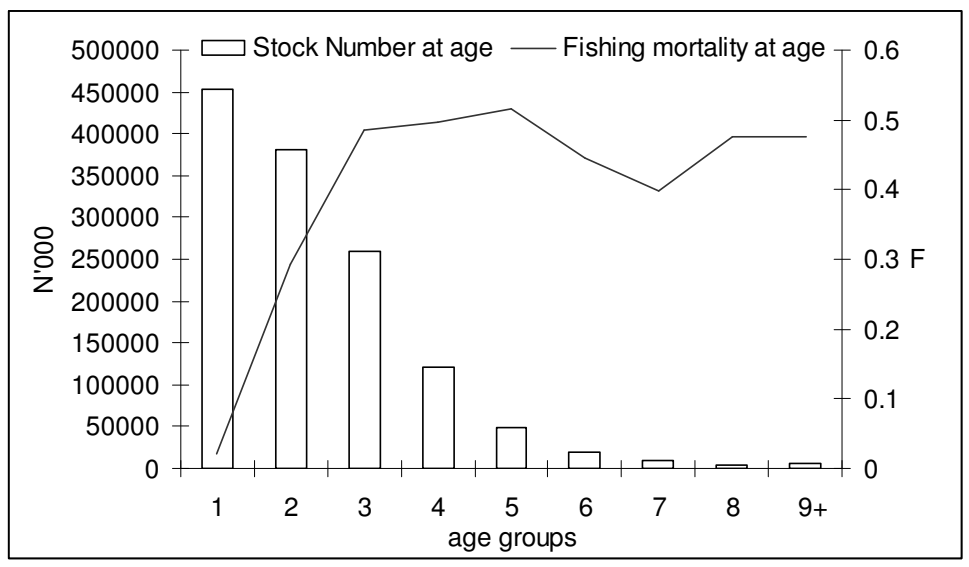

Figure 3: Nephrops Stock number at age and Fishing mortality at age 2003 (ICES, 2004)

In spite of improvement of the Nephrops stock status, ICES (2004) still states an overexploitation of the stock with regards to maximum sustainable fishing mortality $\left(\mathrm{F}_{\max }=0.2089\right.$ compared to $\mathrm{F}_{\text {fleet }}=0.3352$ ). Fishing mortality should be reduced by at least $38 \%$ (ICES, 2004). 
Age compositions of removals (dead catches) are reconstituted from length composition using the slicing technique. An age-based assessment is then performed by a Virtual Population Analysis using Extended Survivors Analysis (XSA). As young age groups constitute the main part of the catches, the fishery is considered too dependent on recruitment fluctuations. ACFM (ICES, 2004) advised improving the survival rate of recruits in order to increase spawning stock biomass.

\subsection{The bio-economic model}

Based on the previous description steps, a bio-economic simulation model was developed in order to carry out cost-benefit analyses of several selectivity scenarios. The conceptual model is given in Figure 4.

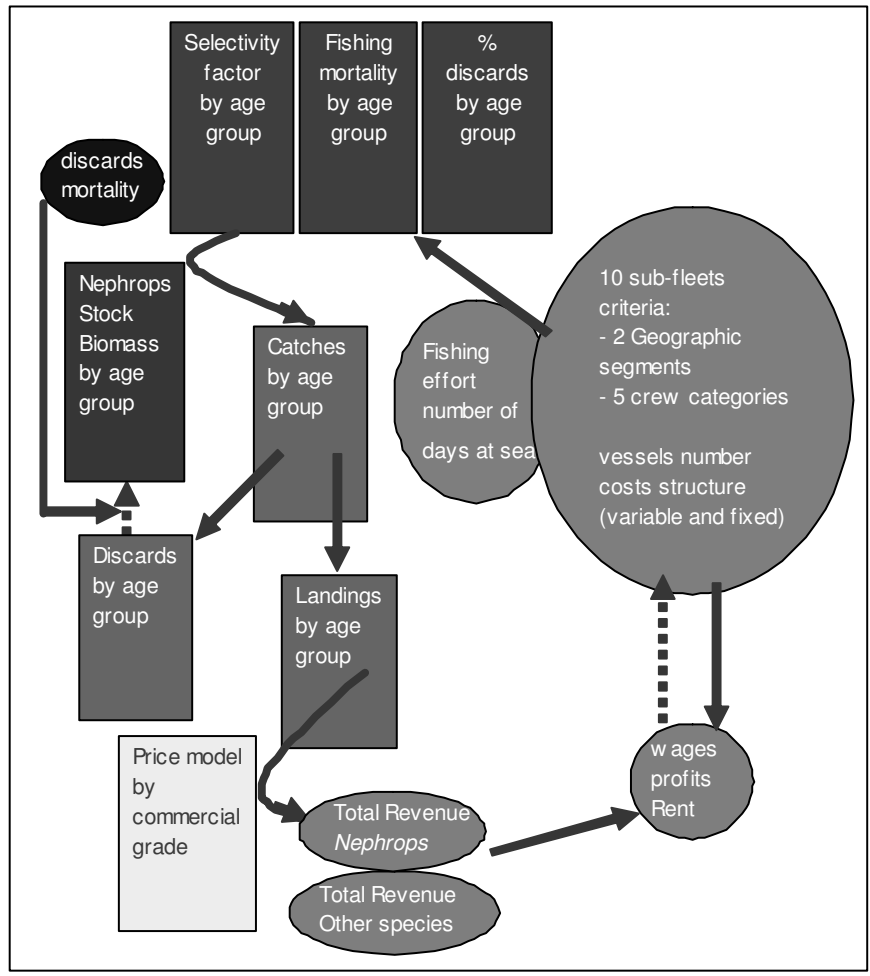

Figure 4: Schematic representation of the bio-economic model. Round boxes refer to global parameters or indicators. Rectangular boxes refer to matrix of parameters per age groups or commercial grades.

The model is structured by age groups for the Nephrops stock and takes into account ten different sub-fleets exploiting the Nephrops stock. Dynamics of the other species harvested by the trawlers are not taken into account in the analyses; either because the mortality contribution of the Nephrops fleet to these species is low or because the fishing mortality mainly concerns the young age groups. In these cases, the impacts of change in selectivity on these species are very limited or benefit only other fleets.

Selectivity scenarios tested consist in varying the selectivity factor. All things being equal, improved selectivity reduces the fishing mortality applied to the Nephrops stock. Based on input sub-fleet fishing mortality, the model provides Nephrops catches, discards and landings per sub-fleet. Nephrops fishing mortality per age group takes account of the survival rate of discards (Guéguen and Charuau, 1975) following Mesnil (1996). Prices are defined by grades as a function of total landings per grades and gross revenue is calculated for each sub-fleet. 
According to the revenue-cost structure of each sub-fleets and the nominal effort, economic indicators such as gross surplus and producer rents are calculated

\section{Nephrops stock dynamic and fishing mortality}

The dynamic of the Nephrops stock is described by a biological model structured by age groups using the classical survival equation of Beverton and Holt (1957) (Gulland, 1983; Hilborn and Walters, 1992). $F_{i}$, with $i$ used as a subscript for age groups, is the instantaneous rate of "nominal" (catch related) fishing mortality defined as:

$F_{i}=E \cdot S_{i} \cdot q$

With $E$, a function of the nominal effort, $S_{i}$, the selectivity per age group and $q$, the catchability.

$K_{i}$ corresponds to a correction factor for survival part of the discards, given by :

$K_{i}=\left[1-s\left(1-d_{i}\right)\right]$

With $d_{i}$ the proportion of discards and $(s)$ the survival rate of discards assumed to be constant for all the age groups.

$K_{i}$ is applied to the "nominal" fishing mortality $F_{i}$ to obtain the fishing mortality of removals (landings and dead discards) $F_{i} \cdot K_{i}$. As we assume constant discarding behaviour and survival rate along the simulation, $K_{i}$ also remains constant.

The total mortality rate $\left(Z_{i}\right)$ used to describe the dynamic of the Nephrops stock is defined as:

$Z_{i}=M_{i}+S F_{i} \cdot F_{i} \cdot K_{i}$

With $\left(M_{i}\right)$, the natural mortality rate, and $\left(S F_{i}\right)$ a selectivity factor by age group taking the value 1 or 0 and defined to test selectivity scenarios. When $S F_{i}=1$, selectivity properties remain unchanged equal to $S_{i}$, when $S F_{i}=0$, selectivity for the age group i is complete.

We assume, for simulation, that $S_{i}$ and $q$ are constant for each sub-fleet, $E$ being constant or endogenous (see below).

As discarding rate is not known per sub-fleet, we assume that discarding rate is the same for each sub-fleet, equal to the discarding rate of the whole fleet and assumed to be constant over the simulation period.

For the same reason, fishing mortality is allocated between the sub-fleets according to their contribution to total landings instead of catches. 


\section{Catches, landings and discards per sub-fleet}

From the fishing mortality per sub-fleet, catches per age group $i$ (in numbers) per sub-fleet are calculated for each time step using the conventional catch equation. Catch in weight $Y$ per subfleet is given by:

$$
Y=\sum_{i} w_{i} \cdot C_{i}
$$

With $\left(w_{i}\right)$, the mean weight at age calculated by using the Von Bertalanffy growth curve and the length-weight relation parameters estimated by ICES (ICES, 2000). Discards per age group in weight $\left(D_{i}\right)$ are derived from the Nephrops catches $\left(C_{i}\right)$, the percentage of Nephrops discarded in number per age group $\left(d_{i}\right)$ and the mean weight at age so that:

$$
D_{i}=w_{i} \cdot C_{i} \cdot d_{i}
$$

Discarding rate is assumed to be constant over the simulation period and to be the same for all the sub-fleets. Landings per age $\left(L_{i}\right)$ in weight per sub-fleet are deducted by subtracting discards from the catches.

The output of the biological model enables Nephrops catches, landings and discards (dead or total) per age group to be calculated per sub-fleet for different selectivity measures simulated, for each year of the simulation.

\section{Revenues and costs, gross surplus and net present value of producer surplus}

Nephrops Gross revenue per sub-fleet $\left(G N_{f}\right)$ is the product of Nephrops price $\left(P_{i}\right)$ and landings $\left(L_{f, i}\right)$ for the different age groups $i$ :

$$
G N_{f}=\sum_{i} P_{i} \cdot L_{f, i}
$$

Price per grade is endogenous to the model. If $\mathrm{c}$ is the grade corresponding to age group $i$ (a grade is an aggregation of several age groups i) the price for grade $\mathrm{c}$, i.e. the price for all age groups $i$ belonging to grade $\mathrm{c}$, is given by:

$P_{c}=\alpha_{c} \cdot L_{c} \beta_{c}$

With $P_{c}=P_{i}$ for $i \in c$

$\alpha_{c}$ is a constant for commercial grade c, $\beta_{c}$ is the price elasticity parameter for grade $\mathrm{c}$ and $L_{c}$ is the amount of landings of grade $\mathrm{c}$ for the total fleet so that:

$$
L_{c}=\sum_{i \in c} L_{i}
$$


The total gross return $G_{f}$ of each sub-fleet per year is given by:

$G_{f}=G N_{f}+G O_{f}$

With $\left(G O_{f}\right)$ the gross revenue of the by-catches species assumed to be constant over the simulation period.

$G_{v}=\frac{G_{f}}{V_{f}}$ is the average revenue per vessel $(v)$ of each sub-fleet, $V_{f}$ being the number of vessels in the sub-fleet $(f)$.

The net revenue per vessel $(v)$ is given by:

$N R_{v}=\left(1-l c_{v}\right) \cdot G_{v}$

With $l c_{v}$ representing the landing cost rate.

The net return to be shared per vessel is the difference between the net revenue and the shared costs $\left(S C_{v}\right)$ :

$R S_{v}=N R_{v}-S C_{v}$

With the shared costs defined as:

$S C_{v}=$ fuelc $_{v} \cdot E_{v}+$ baitc $_{v}+$ icec $_{v}+$ foodc $_{v}$

Fuel cost is function of nominal fishing effort $E_{v}$ and fuel cost per unit of effort ( fuelc). Other shared costs (bait, ice and food costs) are supposed to be independent of the effort of the sub-fleet. As remuneration of production factors (capital and labour) is based on the shared-system, the crew share and vessel share are derived from the net revenue to be shared.

$C S_{v}=c s_{v} \cdot R S_{v}$

$V S_{v}=\left(1-c s_{v}\right) \cdot R S_{v}$

With $\left(c s_{v}\right)$ the share rate and $0 \leq c s_{v} \leq 1$

The labour surplus for each vessel of the sub-fleet is the difference between the net crew share $\left(N C S_{v}\right)$ and the opportunity cost of labour $\left(O L_{v}\right)$, (i.e. the income earned from next best alternative in the economy).

$L S_{v}=N C S_{v}-O L_{v}$

With $N C S_{v}=C S_{v}-i c . n$

(ic ) being the social insurance unit cost and $\left(n_{v}\right)$ the vessel crew size 
and $O L_{v}=n_{v} \cdot h_{v} \cdot c l$

$\left(h_{v}\right)$ being the number of hours spent at the fishing activity and $(\mathrm{cl})$, the hourly unit price of labour elsewhere in the economy assumed to be the same for all the sub-fleets

The Vessel gross surplus for each vessel of the sub-fleet is the difference between the vessel share and the variable costs of the effort (gears) $(V c)$ and the fixed costs (insurance, firm management costs, etc.) ( $F c)$.

$G S_{v}=V S_{v}-V c_{v} \cdot E_{v}-F c_{v}$

Capital surplus earned by the vessel owner is the difference between the vessel gross surplus, the annual capital depreciation $D c_{v}$ and the opportunity cost of capital $O K_{v}$ :

$C S_{v}=G S_{v}-D c_{v}-O K_{v}$

With $D c_{v}=k \cdot K_{v}$.

$(k)$ is the depreciation rate and $\left(K_{v}\right)$ the value of the vessel

and $O K_{v}=i r . K_{v}$

With (ir ) the interest rate

The main indicator for the cost-benefit analysis is the producer surplus or rent. The producer surplus for each representative vessel is the sum of the labour surplus and the capital surplus:

$P S_{v}=L S_{v}+C S_{v}$

From the average revenue per vessel per sub-fleet and the cost structure per sub-fleet, the previously described economic indicators are calculated for each time step in the model per mean vessel by sub-fleet. The total producer surplus or rent $\mathrm{R}$ for the Nephrops fleet and the time step $\mathrm{t}$ is obtained by summing the rent per sub-fleet $\mathrm{f}$ :

$R_{t}=\sum_{f} V_{f, t} \cdot P S_{f, t}$

The net present value of different selectivity scenarios discounts, for a given rate $r$, the annual total rent flows over the simulation period $t=1, \ldots, T$ and is calculated according to the following equation:

$N P V=\sum_{t=1}^{T} R_{t} /(1+r)^{t}$

\section{Static and dynamic model of effort}

Two sets of fleet dynamics sub-models were used to study selectivity scenarios. The first are "static" models, assuming that fishermen do not change their behaviour in response to 
changes in their environment. As a consequence, number of vessels, nominal effort and catchability per sub-fleet are considered fixed over the simulation period. The second sets of model are "dynamic", assuming that fishermen adjust their effort to the prevailing economic conditions.

Mean values for the 2001-2003 period are chosen as reference to describe effort dynamics. Based on similar dynamic models developed in other contexts (Conrad and Bjorndal 1987, Lleonart et al., 2003; Guillen et al. 2004), we assume that fishermen adjust their nominal effort $E_{f, t}$ to the changes in producer surplus according to the following equation:

$E_{f, t}=\left(\frac{P S_{f, t-1}-P S_{f, r e f}}{P S_{f, r e f}}\right) \cdot E_{f, r e f}$

Subject to the following condition: $E_{f, t} \leq E_{f} \max$

Following the principle of adaptative expectancies, current effort $\left(E_{f, t}\right)$ depends on the relative difference between the surplus over the last period $P S_{f, t-1}$ and the surplus over the reference period $P S_{f, r e f}$ but also of the effort of the reference period $E_{f}$,ref . This means that fishermen are encouraged to increase (decrease) their nominal effort, as long as the surplus formed is higher (lower) than the surplus they earn in the next best alternative fishery.

The only constraint is that current effort can not exceed a maximum level of effort $\left(E_{f} \max \right)$ beyond which, vessel can not go to sea because of weather conditions or other technical reasons. As previously described, fishing mortality $F_{i, f, t}$ is a function of $\left(E_{f, t}\right)$, the number of days at sea during year $t$ for the sub-fleet $\mathrm{f}$. The number of vessels being constant, when the effort varies, the fishing mortality is adjusted according to the following equation:

$F_{i, f, t}=\frac{E_{f, t}}{E_{f, r e f}} \cdot F_{i, f, r e f}$

\section{Model parameters}

The stock data used in the simulation are those estimated for 2003 by the ICES Nephrops Working Group, based on results of the 2004 assessment (ICES, 2004). As the aim of the study is to compare results of selectivity scenarios to status quo over the 2004-2015 period, we do not use mean stock values but the 2003 value. The biological parameters of the model are presented in the appendix 1. Mean weight at age is assumed to be constant over the simulation period. Recruitment at age 1 is assumed to occur once at the beginning of the year. It is assumed to be constant over the simulation, to compare potential benefits of the different selectivity scenarios. Recruitment is calculated as the geometric mean of the estimated recruitment over the last ten years $\left(\mathrm{GM}_{1994-2003}=555\right.$ millions individuals $)$ but a low and high recruitments are also included in the simulation for sensitivity analysis. As data on discarding rates per sub-fleet are not available, Nephrops fishing mortality for the whole fleet is allocated by sub-fleet in proportion to sub-fleet Nephrops landings from the reference period 2001 to 2003 instead of their actual catches.

As entry into the fishery is limited by licences, the model assumes that number of vessels remains constant over the simulation. Catchability remains constant over the same period. 
Information on vessel fishing activity (days and hours at sea, etc) and economic information are derived from the annual surveys organized by Ifremer (Berthou et al. 2004). Data used for this paper were collected for years 2001 to 2003 on a representative sample of vessels of each sub-fleet. The structure of revenues and costs per sub-fleet is provided in the appendix 2 . Selectivity measures may imply an increase in gear costs due to either change in gear or adoption of more selective devices. However, we assume in the model that those costs are negligible with regards to the other costs taken into account. The mean long-term interest rate in France over the 2001-2003 periods (4.6\%) was used as a proxy for the opportunity cost of capital and the opportunity cost of labour is calculated using the annual minimum net wage in force. The price model per grade is based on estimations by Metz (2004, personal communication).

\subsection{Selectivity scenarios}

The selectivity scenarios studied in this paper are carried out by varying the selectivity factor as previously described (Table 3). This leads to an improvement in exploitation pattern of Nephrops for the fleet. We assume that selectivity is specific for Nephrops and does not affect catches of other by-catch species. In practice, these improvements could be achieved, either through adoption of selective devices or with mesh size increases. Variations in selectivity tested in our simulations are close to the objectives of several experiments on Nephrops grids (a $13 \mathrm{~mm}$ gap grid, a $15 \mathrm{~mm}$ gap grid and recently a $20 \mathrm{~mm}$ gap grid) which have been carried out since 2004 by the fishing industry and scientifically supervised by Ifremer. These selective devices were tested in order to increase the escapement of the smallest Nephrops, without impacting other valued by-catches. We assume that the same selectivity is applied to each sub-fleet.

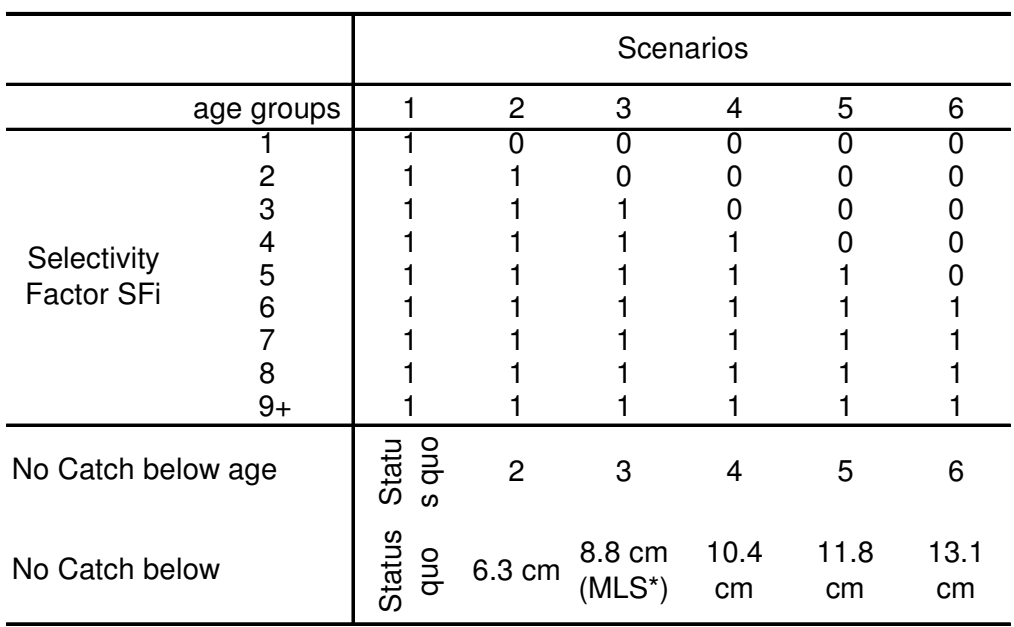

*Minimum Landing Size

Table 3: Selectivity scenarios used for the simulations

The status quo (scenario 1), used as a reference scenario, does not change the exploitation pattern of the fleet. Scenarios from 2 to 6 assume that there is no catch (therefore no discard) of Nephrops under age 2 to 6, respectively (see Table 3 for corresponding Nephrops lengths). Scenario 3 assumes no catches of Nephrops under age 3. The size limit between age 2 and 3 corresponds to a Nephrops length of $8.8 \mathrm{~cm}$, which is the Minimum Landing Size established by the current regulation. Scenario 3 is equivalent to a scenario assuming no catch and no discard of Nephrops below minimum landing size. We assume that changes in selectivity 
factor are implemented in 2004. The potential impacts of these selectivity scenarios on the evolution of discards, biomass, landings, gross revenue, average gross surplus per vessel, and producer surplus of the fleet are analyzed over the 2004-2015 simulation period. Results are compared to status quo.

\section{Results}

\subsection{Steady state equilibrium}

Based on the assumptions of the biological model (notably constant recruitment hypothesis) and on the assumption that fishing effort is exogenous and remains constant throughout the simulation period, equilibrium is reached after a relatively short time period, between 5 and 7 years. Status of the fishery at the end of the simulation is given in Figure 5 for each selectivity scenario compared to status quo.

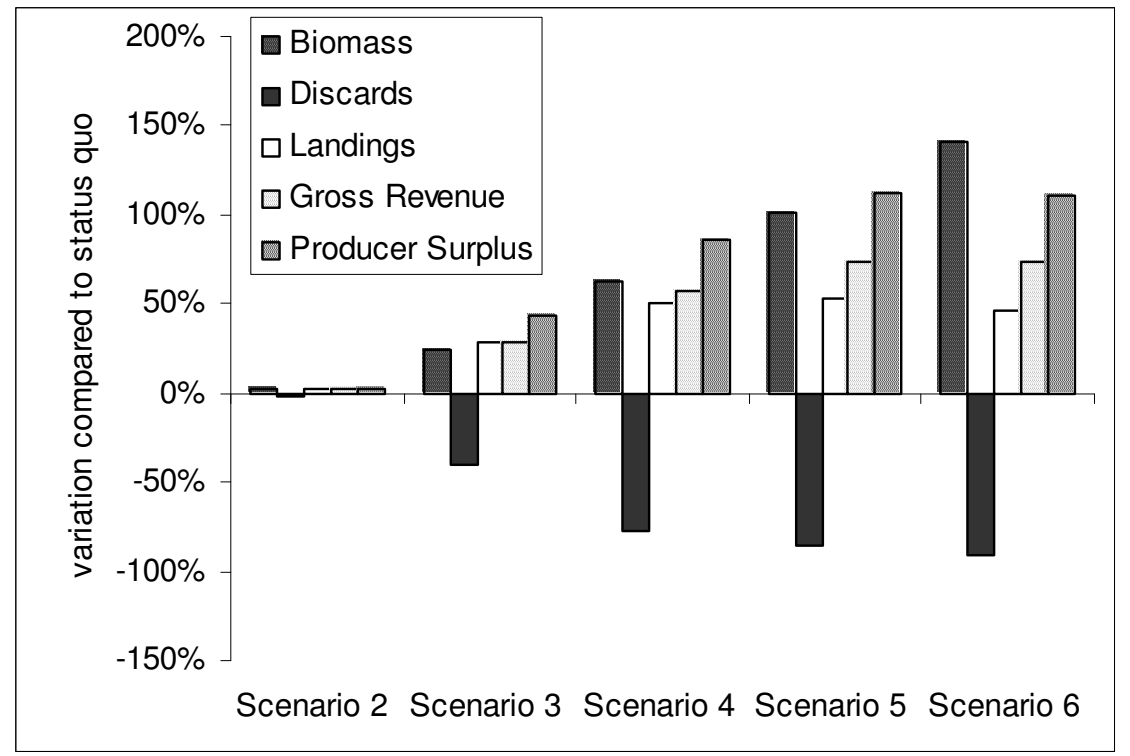

Figure 5: Indicators in the last year of simulation as a function of selectivity scenarios in comparison with status quo

Concerning discards, status quo and scenario 2 are almost equivalent. Scenario 3 reduces discards by $40 \%$ and scenarios 4,5 and 6 reduce discards by $77 \%, 85 \%, 90 \%$ respectively. These are low levels compared to the current 1200 tonnes of discards per year. According to simulations carried out, changes in exploitation pattern with constant nominal effort have positive impacts on biomass. By adopting scenario 3, biomass is restored up to the highest values of the series. In the case of scenario 5, biomass would be multiplied by two. In terms of landings and revenues for the fleet, consequences of scenario 2 on landings and revenues are close to those provided by status quo scenario. Compared to status quo, scenario 3 provides at equilibrium, a 30\% increase in landings and total revenue (4700 tonnes and 41 million euros, respectively). More selective scenarios 4, 5 and 6 also benefit the different subfleets at equilibrium compared to status quo but, beyond scenario 5, landings at equilibrium are not all the higher as the scenario is selective. Lower landings for scenarios 5 and 6 , compared to scenario 4, are however partly compensated by an increase in price. This implies a quasi stabilization in total revenue and producer surplus of the fleet (55 and 42 millions 
euros respectively). The fleet may therefore benefit from a $112 \%$ increase in producer surplus without any change in nominal effort.

\subsection{Transition phases}

Despite long-term benefits to the stock and the fleet, it is generally mentioned by the industry that the fleet has to cope with economic losses during the transition phases towards equilibrium. Simulations of scenario 3 indicate that there is no short-term decrease but increases in landings. Indeed, escapement mainly concerns discards. Subsequent biomass increase quickly improves catches per unit of effort and therefore landings of the fleet (Figure 6). However, landings reduction during the first year is $12 \%, 47 \%$ and $73 \%$ for scenarios 4, 5 and 6, respectively. These negative impacts on landings are however mitigated in terms of revenues by positive price effects. Increase in price when quantities landed are lower can indeed contribute to offset the potential short-term decrease in landings. Besides elasticity price-quantity, an improvement in landings quality might be observed when adopting a selective device. However revenues changes are significant for scenarios 5 and 6 . The higher is the escapement due to the selectivity the longer are the negative impacts on landings and revenues (Figures 6-7).

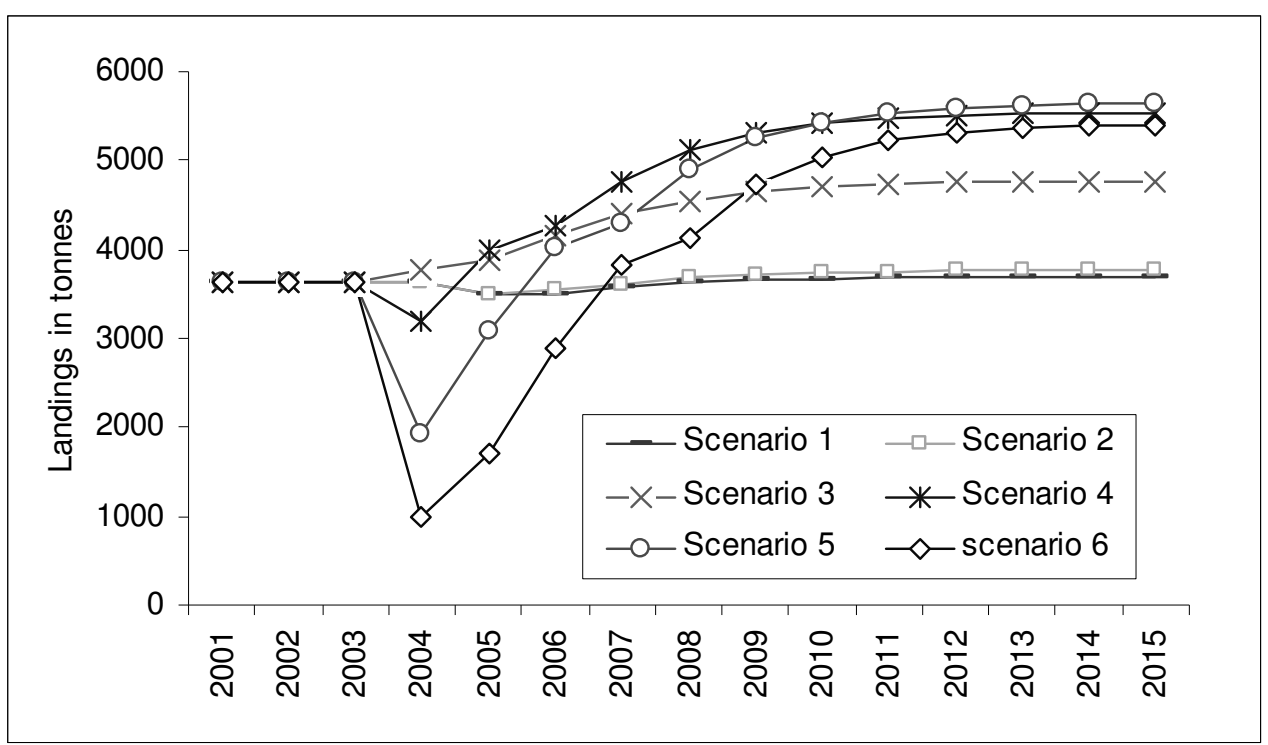

Figure 6: Evolution of the Nephrops landings 


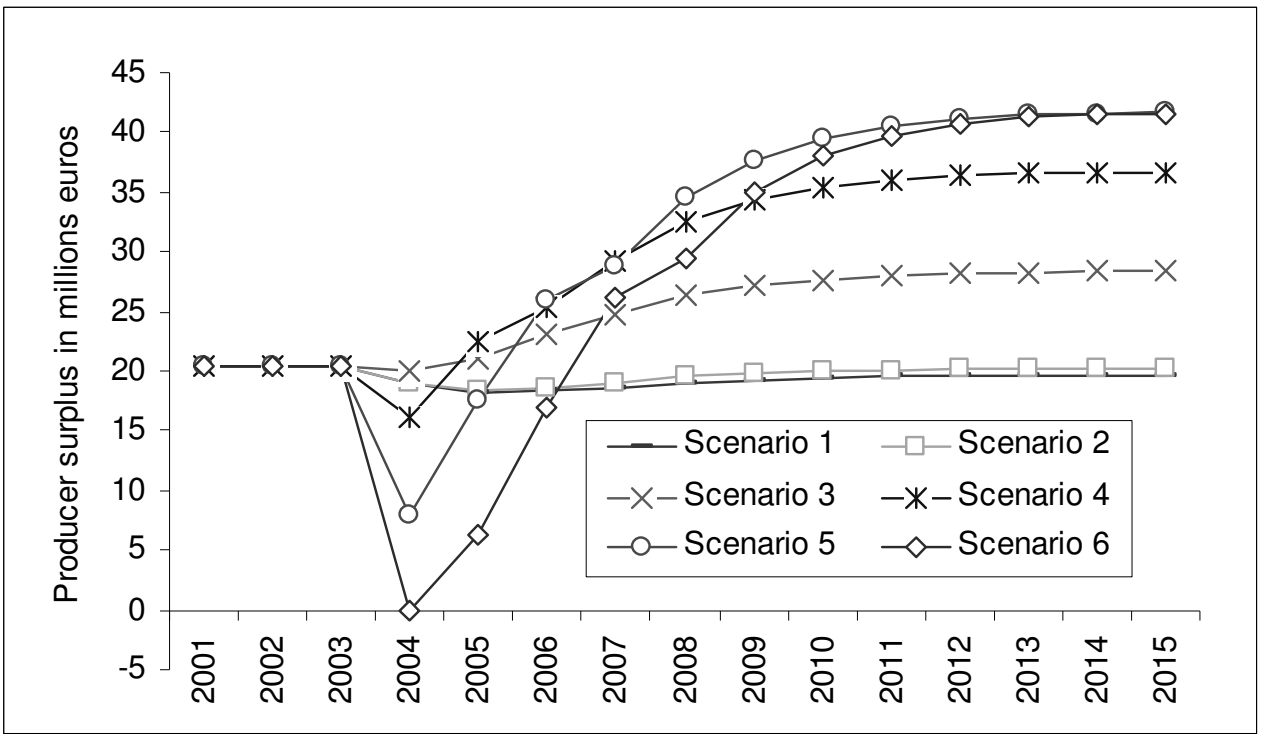

Figure 7: Evolution of the producer surplus

As shown in figures 6 and 7, significant increases in landings and producer surplus follow short-term reductions, even under the "reasonable" scenario 3. These long-term gains may mitigate the short-term losses, if any.

Transition phases can be critical for short-term viability of the sub-fleets. Gross surplus is a relevant indicator for this issue (Figure 8-9).

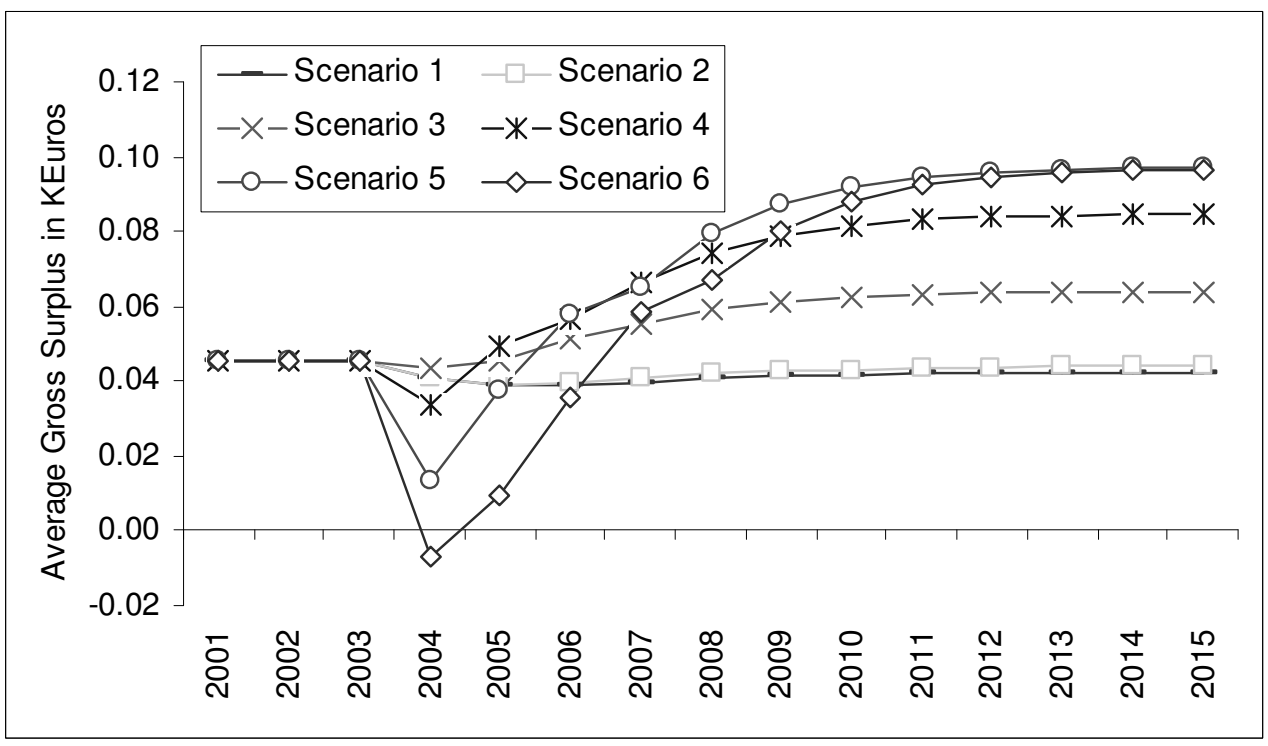

Figure 8: Evolution of the average gross surplus of the 3 crew size vessels in the northern region. 


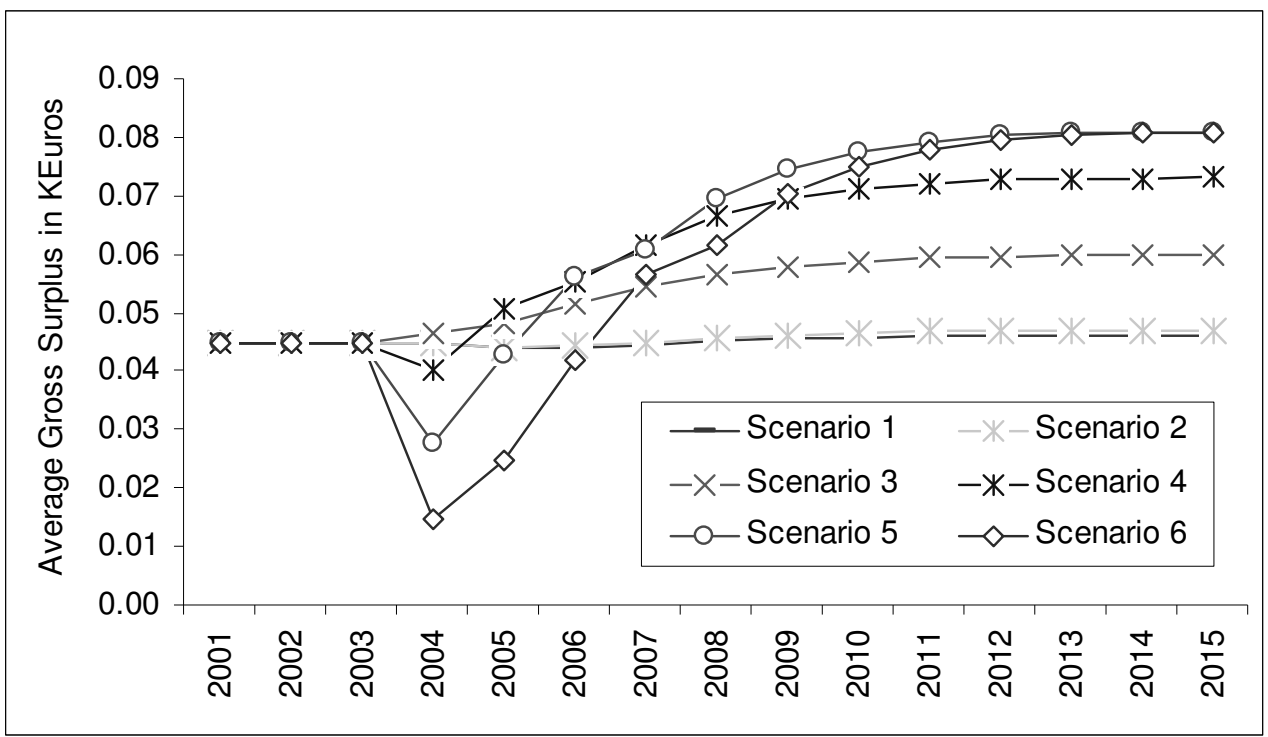

Figure 9: Evolution of the average gross surplus of the $3 \mathrm{crew}$ size vessels in the southern region.

The biggest constraint for vessel owners is to pay back their loans with their current gross surplus flow. They also have to save funds to compensate for capital depreciation in order to have possibility of investing in a new boat at the end of its life time. This constraint can be delayed over several years. If the fishing firm gross surplus is negative or too low to cover the interest payments, then viability of the firm could be threatened. As illustrated in figure 8 , the average gross surplus of the 3-crew-size vessels from northern region is negative in 2004 for scenario 6. It is below the level required to pay back average loans level of these firms $(0.02$ kEuros). This means that fishing firms would have to cope with this by drawing from their available treasury funds.

Segmentation by sub-fleets underlines that distribution of the gross surplus and rent is not equal between sub-fleet. Transition phases can be critical for sub-fleets while not for other. In case of scenario 6, average gross surplus is thus negative in 2004 for northern vessels but positive for southern vessels. Average gross surplus of sub-fleets is improved according to the sub-fleets. Gross surplus increase of 3-crew-size vessels from northern region is around 52\% and only $30 \%$ for same-crew-size vessels from southern region. Southern vessels are indeed less sensitive to an improvement in stock status than northern vessels. Nephrops indeed represent a lower share of landings and gross revenues for southern vessels.

In order to take into account dynamics of fishing effort, runs assuming endogenous effort were also carried out. The model then assumes that each fisherman adjusts his effort according to his individual surplus growth. Total landings of the fleet in case of endogenous effort can be compared with landings in case of constant effort (Figure 10). 


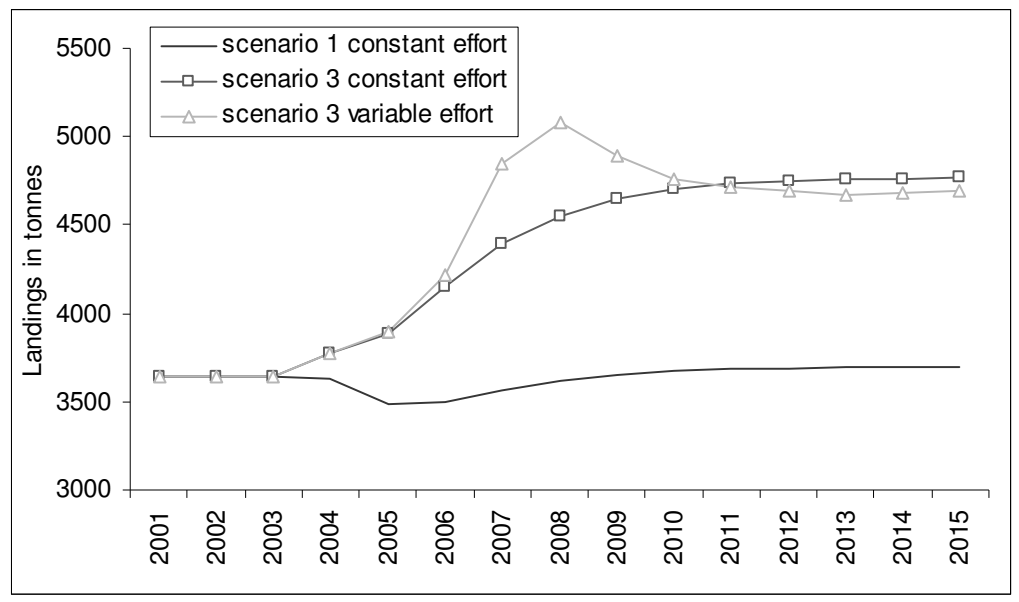

Figure 10: Difference in total landings in tonnes between Scenario 3 at constant effort and Scenario 3 with endogenous effort

In that case, we observe that the increase in effort explained by equation 25 induces higher total landings during the first years of the simulation. Then, effort stabilizes to the upper limit of $E_{f \text { max }}=260$ days at sea per year and total landings decrease. Analyses of landings per unit of effort (LPUE) show that an increase in effort decreases LPUE. As a consequence, surplus per effort unit decreases (Figure 11).

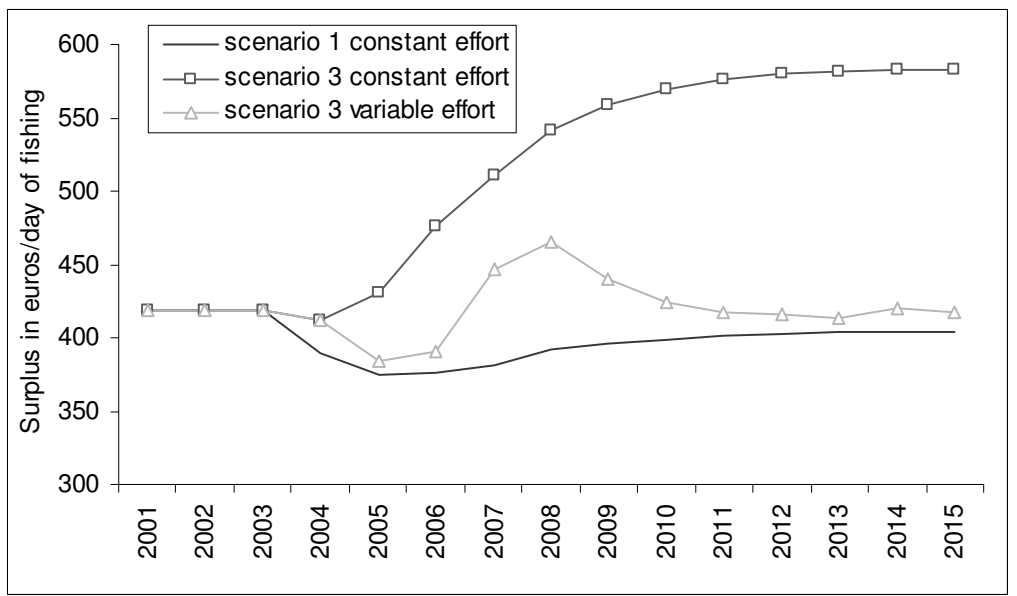

Figure 11: Difference of Surplus per effort unit (day of fishing) in euros between Scenario 3 at constant effort and Scenario 3 with endogenous effort

When fishing effort increases, surplus per effort unit remains below the surplus corresponding to constant effort throughout the simulation periods. By taking account of increasing effort dynamics, we highlight the dissipation of the surplus and underline the need to manage fisheries by selectivity measures together with access regulation.

\subsection{Cost-benefit analysis}

The cost-benefit analysis is carried out by using the classical net present value formula (see equation 24). This formula converts the future expected net income flows for the fleets to a present value amount. Net present value calculations for selectivity scenarios are based on different assumptions for discount rate. Discount rate measures the time value of money for decision-makers or fishery managers initiating the selectivity project. By applying a discount 
rate, more weight is given to earlier costs and benefits than later ones. Simulation results show that whatever scenario is selected, the fishery provides positive producer surplus or rents. The net present value of producer surplus over the 2004-2015 periods is calculated for the six scenarios according to different discount rates (Figure 12).

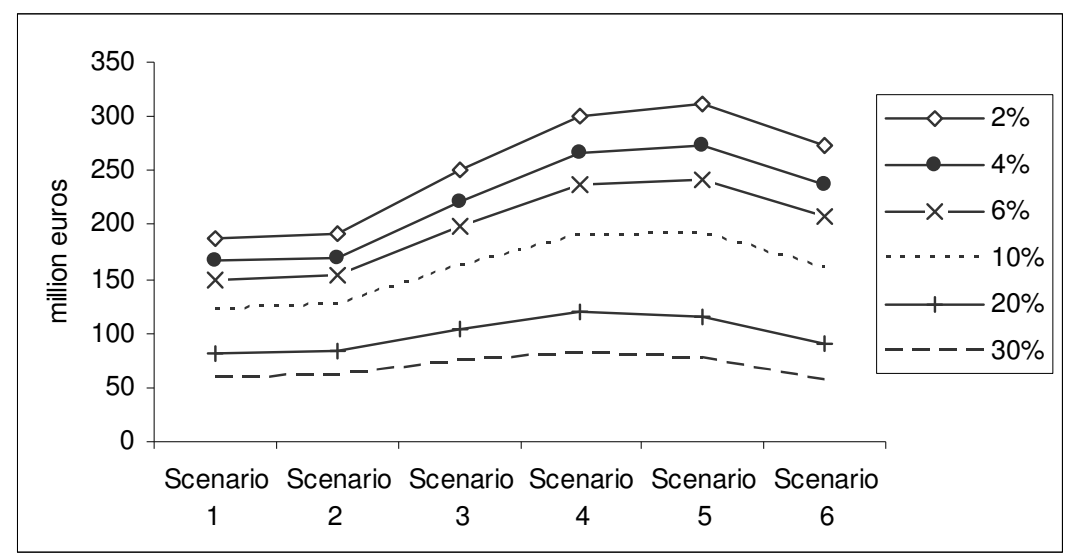

Figure 12: Net present value of producer surplus (rent) in million euros over the 2004-2015 period according to discount rates between $2 \%$ and $30 \%$.

We observe that, for low discount rates, the net present value of producer surplus is higher when the scenario is more selective, except in the case of scenario 6 that leads to important short-term losses. Adopting more selective gears may benefit the fleet but optimal scenario changes as a function of the discount rate. When the rate becomes higher (up to 10\%), it may be preferable for producers to adopt a selectivity corresponding to scenario 4 instead of scenario 5. However we have to consider very high discount rates to find a selective scenario worse than status quo. This case only occurs for scenario 6 and for a $30 \%$ discount rate. One important problem is therefore to choose the relevant interest rate; Arrow et al. (1996), and Portney and Weyant (1999) have discussed this issue. They suggest adopting an opportunity cost approach for cost-benefit analyses of public projects especially projects aiming at reducing environmental impacts (pollution, etc.). A $4 \%$ rate is recommended. This rate is also used by many public agencies to assess their projects.

In our case study, public authorities could be the European Union, the French government or regional public authorities, interested in "investing" in this type of public project. "Investment" would correspond to lend to fishermen in order to compensate their short-term economic losses compared to status quo. This type of public aid is permitted in the context of the Common Fisheries Policy, for compensations when fisheries are closed or effort reduction is imposed. In our case, scenario 5, providing the highest discounted rent (274 million Euros) would be the best choice. The net benefit of this scenario is $74 \%, 23 \%, 3 \%, 15 \%$ higher than status quo, scenarios 3, 4 and 6 , respectively. If fishermen or their representative organizations decided by themselves to borrow money from banks in order to cover shortterm reduction in producer surplus or gross surplus., they would not get a $4 \%$ interest rate as this would include an extra risk premium. For interest rates up to a $12 \%$, the best option is always scenario 5. This would provide 171 millions Euros rent over the 2004-2015 period. Above $12 \%$ interest rate, scenario 4 should be preferred.

Scenario 3 could lead to improve Nephrops stock status with regards to the maximum sustainable fishing mortality without inducing any losses. This scenario indeed assumes no 
catch on the two younger age groups that are usually discarded. Taking into account a $4 \%$ discount rate over the 2004-2015 period, a selectivity corresponding to scenario 3 would generate an average rent of 234 keuros per vessel. In this kind of fishery characterized by high levels of discard, recovering the stock and increasing the value obtained from the production potential, might therefore produce a positive net benefit. However, these results are to be mitigated. They do not consider any increase in the effort as a consequence of increasing rent for the fleet. The selectivity scenario 3 was thus carried out with endogenous effort. It shows that, if benefits of selectivity are reinvested to increase nominal effort, they dissipate rapidly. The fleet rent formed by scenario 3 is higher in the case of constant effort (222 million euros net present value over the 2004-2015 periods assuming a 4\% discount rate) than in the case of endogenous effort (214 million euros). Surplus per mean vessel in case of scenario 3 assuming endogenous effort is 36 keuros lower than the surplus of the same scenario at constant effort (198keuros versus 234 keuros assuming 4\% discount rate for 2004-2015 period). Rent per mean vessel is reduced by $15 \%$ and this is to be linked to the surplus per effort unit evolution presented in the previous section.

Assuming constant recruitments over the whole simulation period is a strong hypothesis. It may be reasonable for stocks exploited at a level where spawning biomass is not reduced to a low level. While this hypothesis is probably valid in the case of constant effort, this may not be the case for variable effort simulations. An alternative way would be to incorporate a stock-recruitment relationship, which would explicitly predict the recruitment level based on current spawning stock biomass. However, no stock-recruitment relationship has yet been established for the Nephrops stock (ICES, 2000). Sensitivity analyses on the recruitment level were therefore carried out. Assuming high recruitment and low recruitment, we show that rent formed by selective scenario is always preferable to status quo, what ever recruitment is assumed (low or high) (Table 4).

\begin{tabular}{lll}
\hline & Status quo & Scenario 3 \\
\hline Low Recruitment & 157 & 209 \\
300 millions individuals & & \\
\hline Mean Recuitment & 167 & 222 \\
GM1994-2003=555 millions individuals & & \\
\hline High Recruitment & 177 & 235 \\
800 millions individuals &
\end{tabular}

Table 4: Comparison of fleet producer surplus (rent) with several recruitment hypothesis for status quo and selective scenario 3 (net present values over the 2004-2015 period assuming a 4\% discount rate).

Sensitivity analyses of fishing effort versus selectivity were also carried out in order to analyze consequences of endogenous effort and to illustrate complementarities between selectivity and effort limitation (Figure 13). 


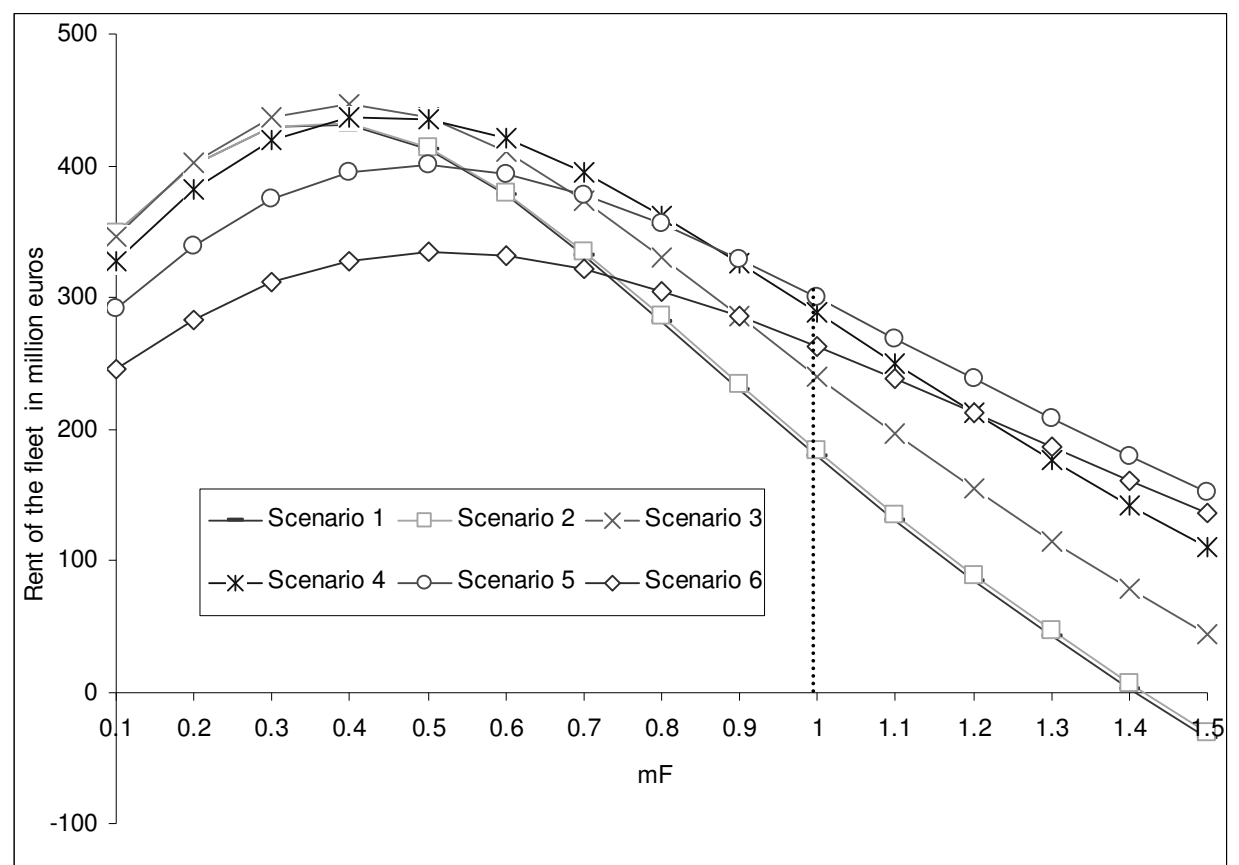

Figure 13: Net present values of producer surplus (rent) over the 2004-2015 period assuming a 4\% discount rate for the six selectivity scenarios and for a multiplying factor of the fishing mortality $\mathrm{mF}$ varying between 0.1 (decrease in effort) and 1.5 (increase in effort).

As shown in Figure 13, increasing effort for a given selectivity scenario would dissipate the rent, except for low levels of fishing mortality. When comparing scenarios together, we can observe that for a range of increase in effort, the rent generated by selectivity measures can remain preferable to status quo. Given a selectivity scenario, rents could be maximized with a reduction in fishing mortality - from to 0.5 and 0.4 - compared to status quo value $(\mathrm{mF}=1)$. Technical measures are therefore not sufficient. A limitation in effort is required to ensure that the rent produced by selectivity measures is not dissipated by an increase in effort.

\section{Discussion}

Selectivity scenarios tested in this study show that potential benefits for the stock and the fleet could be high in fisheries characterized by high discards levels on under-MLS individuals. Total biomass would increase to high values and discards would decrease as no under-MLS Nephrops would be caught any more. However, biomass increase might be not so high as simulated. Indeed, in our simulation model, selective scenarios generate important increase in biomass which may not be possible due to limitations in the ecosystem load capacity. As a result of stock status enhancement and modifications in biomass age structure due to selectivity improvements, landings increase after short transition phases.

Previous works on economic impacts of management measures underlined potential high short-term losses of selectivity measures. Griffin et al. (1993) thus estimated that the introduction of turtle excluding devices in the Gulf of Mexico shrimp fishery would cost an average of US\$1 million, calculated as the net present value of rent losses over a ten-year period. Hendrickson and Griffin (1993) estimated that a device that would remove some fish from the by-catch of the shrimp fishery in the Gulf of Mexico would cost between US\$1.6 million and US\$2.7 million a year in lost rent. In these papers however, all the potential longterm benefits of selectivity improvements are not considered. High short-term losses estimated are the consequence of the decrease in by-catch of valuable species and sizes. The 
adoption of turtle excluding devices does not lead to increase in shrimp catches and changes in landings length distribution (larger fishes) which could mitigate losses in the short term.

Cost-benefit analyses, performed in this work, show however that improving selectivity in fisheries with high discards level of young non-wanted grades of the target species, leads to positive net present values of rent. Assuming constant effort, selectivity improvements with no catch of under-MLS Nephrops, would lead to 234 keuros surplus per vessel compared to status quo (net present value over the 2004-2015 periods assuming a 4\% discount rate). Surplus varies however according to sub-fleet contribution to Nephrops fishing mortality and to its Nephrops dependence. Because of high number of vessels belonging to the Northern fleet-segment (69\% of the Nephrops fleet), Northern sub-fleet benefits from $65 \%$ of the total fleet surplus. However, Northern vessels mean surplus is $6 \%$ lower than total fleet mean vessel surplus whereas it is $12 \%$ higher for the Southern vessels. Modeling several sub-fleets enables to assess cost and benefit distribution. This is a key issue when implementing a management measure.

Accounting for the economic dynamics of increasing effort highlights the limitations of a management only based on technical measures. Selectivity measures are insufficient and do not prevent the "race for fish" (Suuronen and Sarda, 2006). When effort increases, rent is dissipated. Not only conservation of juveniles' production potential is needed but also allocation of the fishing capacity. Right-based approaches are needed to limit overcapacity and to ensure the efficiency of a selectivity measure. A system of individual quotas or licences with a limit on number of days at sea would ensure that the rent formed by selectivity measures will not be dissipated by an increase in effort.

As it is easy to modify gear, in such a way that it complies with legal requirements but does not produce the expected improvement in selectivity, the efficiency of technical measures depends on the "willingness of the fishing industry to accept them" (Suuronen and Sarda, 2006). Existing literature shows that there is a strong incentive among fishermen to circumvent technical measures due to expected short-term losses (scenarios 4, 5 and 6) and cost increases (Suuronen and Sarda, 2006). Ferro and Graham (2000) describe how the mesh size increase in the late 1980s and early 1990s was gradually negated in the UK North sea fishery by the codend design feature that reduced the selectivity. Suuronen and Tchernij (2003) show that in the Baltic cod fishery, widespread gear manipulation to reduce the selectivity of the gear was observed. Tchernij et al. (2004) highlight that if losses are too large, gears will be manipulated and rules will be circumvented (see also Halliday and Pinhorn, 2002).

In the case of fishery like the Nephrops fishery, characterized by a high level of discards on smaller individuals, improving the exploitation of production potential does not necessarily induce short-term losses and negative net benefit. Long-term gains can offset short-term losses (if any). Thus, selectivity, adapted to the minimum landing size of Nephrops would make it possible to reach conservation objectives without inducing short-term losses. In this case, exploitation pattern improvements enable to obtain better pricing of the stock production potential and form a positive rent. However more selective scenarios presented in this paper would meet little compliance among fishermen.

The problem of compliance of fishermen with selectivity measures is also linked to the length of transition period towards more sustainable stock levels. Heikinheimo et al. (2006) underlines the criticisms of fishermen of the pikeperch gillnet fishery against improving 
selectivity measures in the Archipelago Sea in Finland. They argue that it would harm the profitability of the fishery by seriously reducing catches and decreasing prices. Transition phase to positive net present value is too long compared to risks and expected return on investment. It would not be acceptable for the fishermen. In the case of Nephrops, however, length of the transition phase is limited to a few years. Benefits occur quickly after the adoption of a selective device. In any case, the fleet surplus is never below the status quo scenario for more than three years and potential benefits associated are very important. There are no short-term losses or limited short-term losses compared to gains expected. The rapid recovery of the stock induces short length of transition phases. This allows selectivity measures to be efficient in this kind of fishery. A way to limit short-term losses and increase compliance by fishermen would be to implement selectivity measures gradually, by first adopting a $15 \mathrm{~mm}$ gap grid then, after two or three years, a $20 \mathrm{~mm}$ gap grid. Given small short-term losses and gains predicted for the long term, the question of short-term loss compensation has to be discussed with the industry. Another outlook is to consider who would profit from such management measures and how wealth would be distributed. Since Nephrops is not a bycatch in other fisheries and is mainly exploited by French trawlers, the fleet targeting Nephrops would get the long-term gains. One of the perspectives of this study is to analyze the impact of technical measures on the other stocks and the fleets involved in this mixed fishery.

\section{Acknowledgements}

The authors would like to thank B. Mesnil for pre-reviewing this article, C. Brigaudeau for proofreading and the anonymous reviewers for their valuable comments on an early version of this manuscript.

\section{References}

Alverson, D. L., Freeberg, M. H., Murawski, S. A., Pope, J. G., 1994. A global assessement of fisheries bycatch and discards. FAO Fish. Tech. Pap. 339, FAO, Rome, 233 p.

Arrow, K. J., Cropper, M. L., Eads, G. C., Hahn, R. W., Lave, L. B., Noll, R. G., Portney, P. R., Russell, M., Schmalensee, R., Smith, V. K., Stavins, R. N., 1996. Policy Forum on benefit cost analysis. Science 272, 221 - 222.

Berthou, P., Daures, F., Guyader, O., Merrien, C., Leblond, E., Demaneche, S., Jezequel, M., Guegan, F., Bermell, S., VanIseghem., V., 2004. Synthèse des Pêcheries 2002 - Flotte Mer du Nord - manche - Atlantique, $80 \mathrm{p}$.

Beverton, R. J. H., Holt, S. J., 1957. On the dynamics of exploited fish populations. Fish. Invest., 2 (19), Londres. 533 p.

Bjorndal, T., Conrad, J. M., 1987. Capital Dynamics in the North Sea Herring Fishery. Mar. Resour. Econ. 4.

Boncoeur, J., Fifas, S., Le Gallic, B., 2000. Un modèle bioéconomique d'évaluation du coût social des rejets au sein d'une pêcherie complexe. Econ. Prévision V.143-144, 185-199.

Council Regulation (EC) No 850/98 of 30 March 1998 for the conservation of fishery resources through technical measures for the protection of juveniles of marine organisms. Official Journal of the EU L 125, 1-36.

Ferro, R. S. T., Graham, G. N., 2000. A recent UK joint initiative to revise technical conservation measures regulating the design of mobile gears. ICES C.M. 2000/W:5, 6.

Freese, S., Glock, J., Squires, D., 1995. Direct allocation of resources and cost-benefit analysis in fisheries: an application to pacific whiting. Mar. Policy 19, 199-211.

Griffin, W. L., Tolman, D., Oliver, C., 1993. Economic impacts of TEDs on the shrimp production sector. Soc. Nat. Resour. 6, 291-308.

Guéguen, J., Charuau, A., 1975. Essai de détermination du taux de survie des langoustines hors taille rejetées lors des opérations de pêche commerciale. ICES CM 1975/K 12, 6. 
Guillen, J., Franquesa, R., Maynou, F., Sole, I., 2004. The BEMMFISH bio-economic model. IIFET 2004 Japan Proceedings, 12.

Gulland, J. A., 1983. Fish stock assessment: a manual of basic methods, John Wiley, New York, 223 p.

Guyader, O., Berthou, P., Daurès, F., 2007. Decommissioning Schemes and Capacity Adjustment: A Preliminary Analysis of the French Experience. In: R. Curtis, and D. Squires (Eds), Fisheries Buybacks.

Halliday, R. G., Pinhorn, A. T., 2002. A review of the scientific and technical bases for policies on the capture of small fish in North Atlantic groundfish fisheries. Fish. Res. 57, 211-222.

Heikinheimo, O., Setala, J., Saarni, K., Raitaniemi, J., 2006. Impacts of mesh-size regulation of gillnets on the pikeperch fisheries in the Archipelago Sea, Finland. Fish. Res. 77, 192-199.

Hendrickson, H. M., Griffin, W. L., 1993. An analysis of management policies for reducing shrimp by-catch in the Gulf of Mexico. North Am. J. Fish. Manage. 13, 686-697.

Hilborn, R., Walters, C.-J., 1992. Quantitative Fisheries Stock Assessment: Choice, Dynamics and Uncertainty, Chapman and Hall, New York, 570 p.

ICES, 2000. Report of the Study Group on Life History of Nephrops. ICES CM 2000/G: 13, 151 p.

ICES, 2004. Report of the Working Group on Nephrops Stocks, ICES CM 2004/ACFM:19.

ICES, 2006. Report of the Working Group on the Assessment of Southern Shelf Stocks of Hake, Monk and Megrim, ICES CM 2006/ACFM:01.

Kvamme, C., Fröysa, K. G., 2004. Assessing the effects on stocks of selectivity changes in a fishery. Fish. Res. 69, 283-292.

Lleonart, J., Maynou, F., Recassens, L., Franquesa, R., 2003. A bioeconomic model for Mediterranean fisheries, the hake off Catalonia (Western Mediterranean) as a case study. Sciencia Marina. 67, 337351.

Lucena, F., O'Brien, C. M., 2005. The consequences of different scenarios in the management of the gillnet and purse-seine fisheries targeting Pomatomus saltatrix and Cynoscion guatucupa in southern Brazil: a bio-economic approach. ICES J. Mar. Sci. 62, 201-213.

MacLennan, D. N., 1995. Gear selectivity and the variation of yield. ICES J. Mar. Sci. 52, 827-836.

Marchal, P., Andersen, B., Caillart , B., Eigaard, O., Guyader, O., Hovgaard, H., Iriondo, A., Le Fur, F., Sacchi, J., Santurtún, M., 2007. Impact of technological creep on fishing effort and fishing mortality, for a selection of European fleets. ICES J. Mar. Sci. 64, 192-209.

Mesnil, B., 1996. When discards survive: Accounting for survival of discards in fisheries assessments. Aquat. Living Resour. 9, 209-215.

OECD, 1997. Towards Sustainable Fisheries-Economic Aspects of the Management of Living Marine Resources, OECD Publishing, Paris, 268 p.

OECD, 2000. Transition to Responsible Fisheries - Economic and Policy Implications, OECD Publishing, Paris, 298 p.

Pascoe, S., Revill, A., 2004. Costs and Benefits of Bycatch Reduction Devices in European Brown Shrimp Trawl Fisheries. Environ. Resour. Econ. 27, 43-64.

Portney, P. R., Weyant, J. P., 1999. Discounting and intergenerational equity. Resources for the Future, Washington DC, $186 \mathrm{p}$.

Salini, J., Brewer, D., Farmer, M., Rawlinson, N., 2000. Assessment and benefits of damage reduction in prawns due to use of different bycatch reduction devices in the Gulf of Carpentaria, Australia. Fish. Res. 45, 1-8.

Stergiou, K. I., Politou, C.-Y., Christou, E. D., Petrakis, G., 1997. Selectivity experiments in the NE Mediterranean: the effect of trawl codend mesh size on species diversity and discards. ICES J. Mar. Sci. 54, 774-786.

Suuronen, P., Tschernij, V., 2003. The problems encountered in the adoption of improved selectivity in the Baltic cod demersal trawl fishery. ICES C.M. 2003/Z:07, pp. 1-14.

Suuronen, P., Sarda, F., 2006. Evaluation of the role of technical measures in the European fisheries management. EASE in press, $33 \mathrm{p}$.

Tschernij, V., Suuronen, P., Jounela, P., 2004. A modelling approach for assessing short-term catch losses as a consequence of a mesh size increase. Fish. Res. 69, 399-406.

VanMarlen, B., 2000. Technical modifications to reduce the by-catches and impacts of bottom-fishing gears. p. 253-268. In: M. J. Kaiser, and d. Groot (Eds), The Effects of Fishing on Non-target Species 
and Habitats: biological conservation and socio-economic issues., Blackwell Science Ltd. S.J, Oxford, $399 \mathrm{p}$.

Ward, J., 1994. The bioeconomic implications of a bycatch reduction device as a stock conservation management measure. Mar. Resour. Econ. 9, 227-240.

\section{Appendices}

Appendix 1: Initial parameters for the Nephrops stock and fishing mortality Source: ICES, 2004

\begin{tabular}{llllll}
\hline $\begin{array}{l}\text { Age } \\
\text { groups }\end{array}$ & $\begin{array}{l}\text { Fishing } \\
\text { mortality }\end{array}$ & $\begin{array}{l}\text { Mean } \\
\text { weight }\end{array}$ & $\begin{array}{l}\text { Stock } \\
\text { size }\end{array}$ & $\begin{array}{l}\text { Natural } \\
\text { Mortality } \\
\mathrm{i}\end{array}$ & $\begin{array}{l}\text { Maturity } \\
\text { ogive } \\
\text { Oi (2003) }\end{array}$ \\
\hline 1 & 0.0201 & 0.0040 & 452366 & 0.3 & 0.5 \\
2 & 0.2926 & 0.0090 & 380567 & 0.25 & 1 \\
3 & 0.4842 & 0.0170 & 259802 & 0.25 & 1 \\
4 & 0.4971 & 0.0260 & 121356 & 0.25 & 1 \\
5 & 0.5149 & 0.0360 & 48339 & 0.25 & 1 \\
6 & 0.4455 & 0.0510 & 19541 & 0.25 & 1 \\
7 & 0.3981 & 0.0590 & 9159 & 0.25 & 1 \\
8 & 0.4753 & 0.0640 & 4641 & 0.25 & 1 \\
$9+$ & 0.4753 & 0.0700 & 6740 & 0.25 & 1 \\
\hline
\end{tabular}

Appendix 2: Structure of revenues and costs per sub-fleet. Mean 2001-2003 in millions euros. Source: Ifremer-sih

\begin{tabular}{lllllllllll}
\hline & \multicolumn{3}{l}{ North of the Fishery } & \multicolumn{6}{l}{ South of the Fishery } \\
\hline Crew size categories & {$[1 ; 2]$} & {$[2 ; 3]$} & ] $3 ; 4]$ & ] $4 ; 5]$ & ] $5 ;$ & {$[1 ; 2]$} & ] $2 ; 3]$ & ] $3 ; 4]$ & ] $4 ; 5]$ & ] $5 ;[$ \\
\hline Sub-fleets & 1 & 2 & 3 & 4 & 5 & 6 & 7 & 8 & 9 & 10 \\
\hline Gross return & 6.72 & 11.77 & 14.06 & 10.75 & 4.51 & 1.43 & 7.66 & 4.38 & 13.31 & 1.46 \\
Landing costs & 0.25 & 0.64 & 0.67 & 0.59 & 0.25 & 0.05 & 0.42 & 0.21 & 0.73 & 0.08 \\
Fuel costs & 0.72 & 1.59 & 2.18 & 1.63 & 0.69 & 0.15 & 1.17 & 0.65 & 2.01 & 0.20 \\
Bait costs & 0.00 & 0.00 & 0.00 & 0.00 & 0.00 & 0.00 & 0.00 & 0.00 & 0.00 & 0.00 \\
Food costs & 0.03 & 0.18 & 0.31 & 0.28 & 0.10 & 0.01 & 0.13 & 0.09 & 0.34 & 0.03 \\
Ice costs & 0.00 & 0.04 & 0.08 & 0.08 & 0.06 & 0.00 & 0.03 & 0.02 & 0.11 & 0.01 \\
Return to be shared RS & 5.71 & 9.31 & 10.82 & 8.17 & 3.41 & 1.22 & 5.91 & 3.40 & 10.13 & 1.13 \\
Crew share (\% RS) & 2.54 & 4.10 & 4.71 & 3.55 & 1.43 & 0.54 & 2.61 & 1.48 & 4.39 & 0.48 \\
Vessel share & 3.17 & 5.21 & 6.10 & 4.63 & 1.98 & 0.67 & 3.31 & 1.92 & 5.74 & 0.66 \\
Social Insurance costs & 0.27 & 0.43 & 0.51 & 0.34 & 0.18 & 0.06 & 0.32 & 0.15 & 0.42 & 0.05 \\
Crew Premium & 0.09 & 0.46 & 0.64 & 0.44 & 0.09 & 0.02 & 0.34 & 0.19 & 0.54 & 0.03 \\
Other crew costs & 0.30 & 0.49 & 0.58 & 0.36 & 0.13 & 0.06 & 0.36 & 0.17 & 0.45 & 0.04 \\
Opportunity cost of labour & 1.26 & 1.90 & 2.24 & 1.55 & 0.58 & 0.21 & 0.97 & 0.67 & 1.83 & 0.23 \\
Gear costs & 0.31 & 0.55 & 0.71 & 0.50 & 0.26 & 0.07 & 0.40 & 0.21 & 0.61 & 0.08 \\
Gear repair and maintenance & 0.34 & 0.79 & 1.02 & 0.71 & 0.34 & 0.07 & 0.58 & 0.30 & 0.87 & 0.10 \\
Other owner costs & 0.25 & 0.54 & 0.64 & 0.42 & 0.14 & 0.05 & 0.39 & 0.19 & 0.51 & 0.04 \\
Management costs & 0.26 & 0.31 & 0.39 & 0.34 & 0.11 & 0.05 & 0.23 & 0.12 & 0.42 & 0.03 \\
License costs & 0.00 & 0.00 & 0.00 & 0.00 & 0.00 & 0.00 & 0.00 & 0.00 & 0.00 & 0.00 \\
Taxes & 0.02 & 0.04 & 0.04 & 0.03 & 0.01 & 0.00 & 0.03 & 0.01 & 0.03 & 0.00 \\
Depreciation costs & 0.29 & 0.54 & 0.57 & 0.46 & 0.21 & 0.06 & 0.39 & 0.17 & 0.57 & 0.06 \\
Opportunity cost of capital & 0.41 & 0.66 & 0.70 & 0.57 & 0.26 & 0.07 & 0.33 & 0.22 & 0.67 & 0.10 \\
\hline
\end{tabular}

